\title{
El desconocido papel de Estados Unidos en la crisis del Canal del Beagle
}

\author{
Unveiling the Role of the United States in the \\ Beagle canal' crisis
}

Andrés Villar*

\section{Resumen}

La crisis del Beagle (1977-1984) siempre estuvo inserta en un escenario internacional. En otras palabras, nunca fue un caso binario entre Argentina y Chile como muchos estudios han tendido a señalar. Desde el arbitraje internacional pasando por la participación de terceros actores (el Vaticano) y eventos regionales (la guerra de las Malvinas), la crisis del Beagle estuvo localizada en una dimensión internacional mucho más compleja que una exclusiva negociación bilateral. Con todo, factores internos e internacionales condicionaron en diferentes grados la política exterior argentina y chilena. La resolución de la crisis del Beagle ha sido explicada en referencia al rol clave jugado por el Vaticano; sin embargo, recientes documentos desclasificados en Estados Unidos y entrevistas revelan una historia diferente.

PAlAbras Clave: política exterior latinoamericana, disputas fronterizas, crisis del Beagle, resolución de conflicto.

\section{Abstract}

The Beagle Channel crisis (1977-1984) unfolded in a global political context. In other words, it was never solely a bilateral matter between Argentina and Chile, as many analyses have contended. From the in-

1 Investigador Asociado, Centre for Rising Powers, Departamento de Políticas y Estudios Internacionales, Universidad de Cambridge. av350@cam.ac.uk

Recibido el 10 de marzo de 2014; aceptado el 5 de junio de 2014. 
ternational arbitration to the participation of a third actor (Vatican) and the Falklands war, the Beagle crisis had pronounced international dimensions. However, domestic structures and international conditions affected Argentine and Chilean foreign policies in different degrees. The settlement of the Beagle crisis has been explained by reference to the key role played by the Vatican, but recently declassified U.S. documents and interviews with key actors reveal a different story.

KeYwords: Latin American foreign policies, frontier disputes, Beagle crisis, conflict resolution. 
ANDrÉs Villar • El desconocido rol de Estados Unidos en la crisis del canal de Beagle

\section{INTRODUCCIÓN}

El argumento central de este trabajo es que los factores internos e internacionales condicionaron las decisiones y el resultado de la crisis en 1978. Sin embargo, su rol fue disímil en A rgentina y Chile. En el caso argentino, el estudio demuestra que el proceso de toma de decisiones estuvo altamente condicionado por variables internas; en Chile, en cambio, la política exterior fue más sensible a factores internacionales.

El conflicto del Beagle siempre estuvo inserto en un escenario internacional. En otras palabras, nunca fue un caso binario entre Argentina y Chile como han señalado muchos analistas. Desde el arbitraje internacional pasando por la participación de terceros actores y eventos (el Vaticano, el papel de Estados Unidos, el Reino Unido y la guerra de las Malvinas), el conflicto del Beagle estuvo localizado en una dimensión regional e internacional mucho más compleja que una exclusiva negociación bilateral. Así, en diversos grados, los factores internos e internacionales condicionaron la política exterior argentina y chilena. De acuerdo con las condiciones estructurales internas de cada país, la aplicación y resultados de la política exterior variaron según la interacción entre las limitaciones internas y factores internacionales.

El presente trabajo es parte de mi tesis doctoral que fue defendida el 2013 $\mathrm{y}$ tuvo como fuentes primarias entrevis- $\operatorname{tas}^{1}$ y documentos oficiales recolectados en Argentina, Chile, el Reino Unido y los Estados Unidos. En la primera parte del artículo se presenta una breve revisión bibliográfica del conflicto de la que queda de manifiesto que con excepción de los trabajos de Roberto Russell, no hay estudios sobre los aspectos internos como variables explicativas de su solución. A continuación, se examina brevemente el proceso de toma de decisiones en Argentina y Chile. Del primero, se describen las debilidades estructurales a que estuvo sujeta durante todo el período de la crisis; en el caso de Chile, se subraya la falta inicial de cohesión para abordar la crisis y la medida en que en los primeros años el aislamiento internacional afectó el desempeño de su política exterior. Posteriormente, se describe el desconocido rol desempeñado por Estados Unidos en la crisis. A este respecto, salvo los estudios de autores como Fermandois (2005), Escudé y Cisneros (2000) y Lanús (1984) no se ha realizado un análisis más integral. En un contexto de guerra fría y mundo bipolar cabe preguntarse qué papel des-

1 En Argentina: Raúl Alconada, Jorge Battaglino, José Ramón Sanchis, Francisco Corigliano, Santiago de Estrada, Julio Hang, Roberto Russell, Daniel Esteban, Rut Diamint, Andrés Fontana y Susana Ruiz Cerutti. En Chile: Roberto Durán, Francisco Javier Cuadra, María Teresa Infante, Luis Maira, Francisco Orrego Vicuña, Ángel Flisfisch, Marco Robledo, Ernesto Videla, Patricio Pozo, Pedro Suckel, Joaquín Fermandois, Augusto Varas, Alberto van Klaveren y Manfred Wilhelmy. En Estados Unidos.: Robert Pastor y Carlos Portales. 
empeñó el gobierno de Carter a fines de los 1970. Como se verá más adelante, al nuevo gobierno demócrata no le era indiferente un potencial conflicto en la región. En este sentido, los estudios sobre la crisis del Beagle no habían realizado un análisis acabado sobre el rol de los Estados Unidos.

\section{REVISIÓN BIBLIOGRÁFICA:}

\section{LA FALTA DE ANÁLISIS A NIVEL INTERNO}

Por lo general, las teorizaciones sobre la cooperación/conflicto entre Estados, particularmente la bibliografía anglosajona, tienen como referente, muchas veces no explícito, algo así como el sistema mundial o sistemas de magnitud importante en cuanto al número de sus miembros. Con ese referente, el juego es ya sea entre grandes potencias -el referente casi exclusivo de las teorías neorrealistas-, o uno de coaliciones entre varios países, en que está siempre presente el problema de potenciales hegemonías. Por ejemplo, México y Brasil en distintos periodos en la región. Si se cambia de perspectiva y se elige un caso de relación bilateral, es posible que los enfoques y los escritos más convencionales rindan mucho menos fruto. Cabe señalar desde la partida que difícilmente puede concebirse una relación bilateral, como la de Argentina-Chile como un juego de suma cero. Incluso es difícil hacerlo en relaciones bilaterales acentuadamente asimétricas como la de Argentina-Uruguay.
En relaciones bilaterales como las de Chile-Argentina las cuestiones limítrofes son el punto de partida, y una investigación sobre la forma en que evoluciona la combinación cooperaciónconflicto no puede prescindir de esa variable. Históricamente, en la relación Chile-Argentina esa dimensión ha sido prioritaria: desde un comienzo, lo que explicó la rivalidad no fue una pugna económico-comercial, una colisión de intereses ideológicos, o proyectos de subordinación de uno por el otro sino la fijación de fronteras.

Sin embargo, algunos académicos han atribuido la cooperación argentinochilena a la existencia de una cultura diplomática en la región (Kacowicz, 2005; Hurrell, 1998). Más que en otras regiones del mundo, afirman dichos autores, el sistema diplomático de América del Sur está impregnado de normas jurídicas y de una «cultura» del legalismo. Una de las principales características de la subregión es «el gran número de tratados multilaterales y bilaterales que imponen obligaciones para la solución pacífica de los conflictos» (Holsti, 1996: 170). Según Kacowicz (2005), el impacto de las normas de derecho internacional se hace sentir de dos maneras paralelas e interconectadas. Por un lado, las normas internacionales dan forma a la política exterior de Argentina y Chile, ya que estas «a través de procesos de socialización y de emulación, fueron motivadas por consideraciones de reputación y prestigio en sus relaciones internacionales. Por otra parte, de manera indirecta, 
el derecho internacional influyó en el proceso político interno a través de la internalización de normas en la política exterior» (Kacowicz, 2005: 36). Así, la región es vista como un «área especial» en la que «siempre ha habido una clara voluntad de usar la fuerza pero también una concepción limitada de la fuerza dada su sólida cultura diplomática» (Hurrell, 1998: 532). El presente trabajo tiene una interpretación diferente y se considera que para explicar la decisión de cooperar entre ambos países es un enfoque limitado.

Otra perspectiva importante de la bibliografía disponible es la relacionada con la solución de los conflictos limítrofes. Dicho enfoque ha tendido a centrarse en un aspecto específico, por ejemplo las disputas entre dos países, y deja de lado variables internacionales (Calvert, 1983; Escudé, 1988; Domínguez y otros, 2003; Rojas Aravena 2003; Scenna, 1981). Desde el punto de vista de modelos racionales, los trabajos de Goertz y Diehl (1993) y Huth y Allee (2002), han incluido el conflicto del Beagle en un amplio número de casos de disputas fronterizas. Por su parte, Mares (2001) ha utilizando modelos de teoría de juegos y negociación entre fuerzas militares. En este caso, realizó una investigación con solo dos casos de estudio, Argentina-Chile (conflicto del Beagle) y Ecuador-Perú (conflicto sobre el Amazonas). Este interesante modelo teórico puede ser útil para explicar el uso o no de la fuerza en 1978, pero demasiado restringido para entender la cooperación lograda entre en ambos países durante todo el conflicto.

El análisis de la burocracia diplomática y su papel en la definición de la política exterior ha sido una valiosa fuente para comprender el periodo y los acontecimientos de esos años (Maira, 1985; Muñoz, 1987, Durán, 2003, 2009; Tomassini, 1987, 1991; Varas, 1999; Wilhelmy, 1987; Tulchin, 1984; van Klaveren, 1984, 1997). Asimismo, el papel que desempeñaron las fuerzas armadas en la transición a la democracia en Argentina ha sido una importante fuente de información, que da luces sobre los intereses corporativos de las de ambos países (Novaro y Palermo, 2006; Passarelli, 1998; Agüero, 1998; Puig, 1984; Russell, 2010; Fontana, 1990; Battaglino, 2010, Pencey et al., 2002). En la misma línea, los estudios de seguridad y defensa regional y el papel desempeñado por las fuerzas armadas (Fraga, 1997; Navarro, 1998; Millán, 1983, Morris, 1983, 1989; Mullis, 2006; Varas, 1980), han abordado la crisis del Beagle en forma tangencial. En cuanto a los estudios geopolíticos, se han caracterizado por nociones de suma cero que intentan revelar los reales motivos e intenciones de los vecinos y arrojar sospecha sobre ellos, casi siempre procurando caracterizar a sus propios países como víctimas y exacerbando disputas territoriales de larga data (Niño, 1979, 1985; Escudé, 1988; Meneses, 1991; Morris, 1989; Pittman, 1981; Videla, 2000).

Sin duda, los enfoques históricos y legales han sido fundamentales para 
comprender adecuadamente la crisis. En esta línea, el trabajo de los académicos de Argentina y Chile ha demostrado ser muy relevante (Cisneros y Escudé, 1998; Fermandois, 2005; Morris, 1989, Gallo, 1998, Lacoste, 2003, Lanús, 1984, 1982, Infante, 1984, 1988; Arancibia Clavel y Bulnes, 2004; Sánchez, 1977; Orrego Vicuña, 1989; Rauch, 1999; Alvarez Natale, 1984; Novaro y Palermo, 2006; Tapia, 1998). Los estudios más destacados en esta área son los de Álvarez Natale (1984) y Passarelli (1998) de Argentina y Santiago Benadava (1999) y Enrique Bernstein (1989) de Chile. Importantes fuentes son las memorias diplomáticas escritas por los propios actores durante la crisis. En general se observa, como es natural, defender con energía los argumentos del propio país durante la crisis y poner de relieve el papel desempeñado por el Vaticano. Según el criterio diplomático de cada uno, los autores se inclinan tácita o explícitamente a acusar al otro lado de expansionismo e hipernacionalismo (el ex ministro argentino Camilión 2000; Ernesto Videla, 2000). La importancia de estos trabajos queda de manifiesto cuando se revelan los diferentes enfoques y las disputas internas propias de los países respectivos. Por último, los estudios más importantes sobre el papel mediador del Vaticano son los de Passarelli (1998), Laudy (2000), y Princen (1992). No obstante que hay análisis desde una perspectiva interna (Allan, 1997; Russell, 1990, 2010, Garrett, 1985, Tulchin, 1984; Parrish Randall Jr., 2006) ellos no logran un conocimiento exhaustivo del proceso de toma de decisiones de la política exterior, ya que también dejan de lado las variables internacionales. El único trabajo que se centra en el proceso de toma de decisiones es un artículo de Russell (1990), que ofrece un análisis de las variables internas y en cierta medida del contexto regional. La contribución de este autor es sin duda destacadísima pero en esta oportunidad se trata de ofrecer una reconstrucción amplia del contexto internacional y nacional, rebasando así su enfoque.

El argumento que se desarrolla a continuación consiste en que no obstante que los trabajos antes señalados son una contribución y fuente importante para entender la crisis del Beagle, no bastan para explicar la decisión de cooperar lograda entre Argentina y Chile en 1984, ya sea porque son altamente nacionalistas (Arancibia Clavel y Bulnes, 2004),se centran en el uso de la fuerza en 1978 (Mares 2001), en la idea de una "cultura diplomática" (Kacowicz 2005), o se abordan a partir del rol del Vaticano (Princen, 1992). El presente estudio pretende llenar este vacío de la literatura y ofrecer un análisis amplio e integral de la crisis del Beagle.

\section{MOdelo TEÓRICO}

El presente trabajo sostiene que el contexto político y el marco institucional de cada país son elementos importantes para entender las negociaciones y los desenlaces en el plano internacional. 
En otras palabras, pone de manifiesto la importancia del contexto histórico, regional e internacional para explicar los procesos de toma de decisiones en política exterior. Como definición, entiendo estos como "un complejo proceso de interacción entre diversos actores, incorporados en diferentes estructuras [en donde] su interacción es un proceso dinámico, que genera, una constante evolución de los actores y de las estructuras» (Hill, 2003: 28). En efecto, al introducir este enfoque en el análisis de la política exterior la investigación va más allá del modelo de actor racional unitario. A partir del influyente estudio de la crisis de los misiles en Cuba (1962), se entiende que «la toma de decisiones de un gobierno es un proceso complejo de múltiples actores» (Allison y Zelikow, 1999: 263), que debe ser analizado en profundidad.

Como ya se mencionó, los diferentes estudios han ofrecido una serie de explicaciones sobre la forma en que las relaciones argentino-chilenas pasaron de la rivalidad a la cooperación. Sin embargo, los argumentos no bastan por sí solos para explicar plenamente la disputa fronteriza entre los dos países. Este estudio sostiene que los enfoques sobre toma de decisiones pueden colmar algunas de las lagunas y dar cuenta de las anomalías resultantes a partir de explicaciones sistemáticas en temas de conflictos (Hagan, 2001). Por lo tanto, el interés teórico radica en que examina la influencia de los decisores (agency) en Argentina y Chile que les permitió influir en los resultados. Por lo tanto, se examina el impacto de la política interna en la formulación de la política exterior durante la crisis de Beagle.

Con todo, el análisis pone de manifiesto que la política exterior de Argentina y Chile fue sensible al entorno político y de seguridad internacional en que ambos operaban durante la década de 1970 y mediados de 1980 (Holsti, 1996). Por lo tanto, lógicamente cabe esperar que en ambos gobiernos influyeran tanto las variables internas como las internacionales. Desde el punto de vista teórico, el objetivo es considerar que las opciones de política exterior son potencialmente reflejo de la interacción entre ambas dimensiones. $Y$ es en este punto donde debe destacarse la complejidad del conflicto del Beagle.

Según, Putman (1988) los analistas de política exterior parten de la base de que en casi todos lo temas relevantes los agentes decisorios generalmente no están de acuerdo en cuáles son las exigencias o demandas del contexto internacional y cuáles los intereses nacionales (1988: 432). Sin embargo, este caso de estudio es distinto del ya clásico «juego de dos niveles» de Putman (1988), que analiza cómo se superponen o entrelazan las negociaciones entre dos niveles (interno e internacional). Su modelo sugiere que cuanto mayor es la autonomía de quienes toman las decisiones en el nivel II (actores internos), mayor será el triunfo del conjunto del sistema, y por lo tanto, mayor la probabilidad de llegar a un acuerdo internacional. Este autor sostiene que para ser exitoso todo acuerdo debe estar dentro de un margen 
de tolerancia entre los actores intervinientes del nivel II. Una vez logrado ese consenso interno probablemente será un acuerdo internacional. Sin embargo, en la presente investigación sostenemos que en este caso no se aplica el modelo de dos niveles de Putman puesto que los actores no están mirando al público nacional (constituencies), puestos que ellos mismos son los actores internos con capacidad de veto - me refiero a las fuerzas armadas. En el caso del Beagle, las variables internacionales cumplieron una función de puente en condicionar y dar forma a las decisiones de ambos gobiernos en determinados momentos, por ejemplo en 1978. Sin embargo, a mi juicio en el proceso de toma de decisiones ambos países estaban enfocados en dos dimensiones. En el ámbito subregional, a Chile le preocupaban Perú y Bolivia y, por su parte, Argentina, bajo una fuerte rivalidad con Brasil, lidiaba paralelamente con el tema de las Malvinas. En el ámbito internacional, ambos países intentaban sortear la exclusión internacional. Por distintas razones, el rol de Estados Unidos y del Reino Unido surgió como variable interviniente, particularmente en la primera parte del conflicto (1977-1979) condicionando el nivel II de Putman.

Por consiguiente, creo que otro factor muy relevante es la percepción de los actores nacionales e internacionales en el juego de pesos y contrapesos de poder. En el contexto de la Guerra Fría resulta claro la forma en que se construye normativamente la seguri- dad nacional y en que estos marcos permearon a los decidores. En efecto, en un memorando de la cancillería chilena, el coronel Videla «le hiz[o] ver» al Cardenal Samoré «como la Argentina con el apoyo de la URSS y del grupo de la masonería pretende hacer fracasar la mediación $»^{2}$. En una entrevista realizada en enero de 2012, Videla volvía a destacar la falta de estudios sobre el papel de la Unión Soviética. Así, me parece que la dimensión internacional influyó al advertir sobre la forma en que los poderes regionales y globales actuaron para aplacar un conflicto, particularmente en un tema que afectaba sus propios intereses: en el caso del Reino Unidoi, por las Malvinas; y en el caso de Estados Unidos, para evitar conflictos en su área de influencia.

En este escenario, Pinochet tuvo total autonomía y control para implementar la política exterior chilena. Jugó un partido defensivo porque comprendió rápidamente cómo las condiciones externas estaban afectando sus políticas a largo plazo. En consecuencia, los resultados sugieren que en determinados momentos los factores internacionales desempeñaron un papel decisivo en el traslado del debate interno en esa dirección (conflicto/mediación/cooperación). Por lo tanto, el aspecto más interesante de la crisis del Beagle es la forma en que

2 Fondo Documental volumen 2060. «Entrevista Coronel Videla con Samoré.» Doc Sec. 206, Coronel Videla, Oficina de Mediación, Archivos Ministerio de Relaciones Exteriores de Chile, 29 Mayo 1981 
el debate en el seno de cada gobierno pasó de una visión conflictiva a la decisión de acceder a una mediación y cómo el resultado final, dada la distribución del poder interno, fue aceptado para poner término al conflicto.

El neorrealismo clásico ofrece un persuasivo argumento para estudiar la crisis del Beagle. Sus representantes (Waltz, 1978) enfatizan que el sistema internacional condiciona las definiciones de política exterior, y más aún, es su principal determinante.

Pero de acuerdo con esta corriente eso no significa que los factores de política interna no sean importantes. Los realistas neoclásicos sostienen que en determinados momentos los actores nacionales pueden influir en la forma en que el Estado interpreta las oportunidades y amenazas internacionales, así como en la forma de reaccionar ante ellas (Ripsman, 2009). El realismo neoclásico intenta analizar las características internas de los Estados-en nuestro caso, el grado de autonomía y control con que cuenta un gobierno«para implementar su política exterior en relación a la evaluación que hacen sus lideres tanto de las oportunidades y amenazas internacionales como de la política exterior que ellos mismo persiguen» (Taliaferro et al. 2009, 4).

Esta nueva corriente del neorrealismo busca explicar la variación en un conjunto de decisiones de política exterior de un Estado en un periodo determinado o con similares limitaciones externas enfrentadas por un conjunto de Estados. No tiene la pretensión de explicar patrones sistémicos como los neorrealistas. Así, tomando en cuenta el caso en estudio, una hipótesis articulada desde una perspectiva del neorrealismo clásico tendría que dar luces sobre potenciales reacciones diplomáticas y militares de Argentina y Chile ante las exigencias del sistema internacional, pero no tendría por qué explicar las consecuencias sistémicas a dichas respuestas. Al igual que otros realistas neoclásicos, Lobell $(2009,56)$ sostiene: «abro la caja negra del Estado, tratando al Estado como una variable interviniente». En general, una de las limitaciones de los enfoques neorrealistas y liberales es que descartan la influencia de los líderes políticos (agency) para que otros Estados sean vistos como una amenaza exterior. Qué duda cabe que las condiciones internacionales influyen en las acciones y decisiones de los Estados. Sin embargo, como afirma Sterling-Folker $(1997,19)$ la naturaleza anárquica del sistema «no determina cómo los Estados deben organizar su proceso interno para lograr dichos fines. Los Estados son libres para experimentar, para emular otras prácticas, o no hacer nada. No obstante, los procesos internos son los que actúan como árbitro final para la supervivencia del estado dentro de un entorno anárquico».

En definitiva, la esencia de este paradigma es que no solo la posición de poder de los Estados frente al resto del sistema internacional es la que determina los principales objetivos e intereses de la política exterior. En este 
sentido, la toma de conciencia de los Estados argentino y chileno en cuanto a su poder y posición (status) en el sistema regional e internacional, no solo define en parte qué intereses y objetivos deben privilegiarse sino que constituyen un punto de partida desde el cual sus líderes comenzaron a definir sus estrategias internas y externas respecto de la implementación de su política exterior.

En efecto, en esta crisis pudo determinarse que los actores internos logran influir más en el poder ejecutivo cuando coexisten en un marco de bajo nivel de autonomía estructural. Para los efectos de este estudio, el proceso de toma de decisiones de un Estado se define tanto por una cadena de procedimientos decisorios, una estructura institucional y normas, que determinan en parte el grado aislamiento en que se encuentra la política exterior del Ejecutivo respecto de la oposición y de actores de veto. En otras palabras, como señala Ripsman, "a mayor autonomía estructural del Ejecutivo, menor será la capacidad de los actores nacionales para interferir con la agenda de política exterior de un gobierno" (Ripsman, 2009: 189). Y de hecho, fue el caso del régimen de Pinochet. Sin embargo, a lo largo de la crisis la diferencia de nivel en materia de autonomía y control no varía solo entre Argentina y Chile, sino también en cada Estado. Por ejemplo, en el caso de los gobiernos argentinos, la independencia y control del Ejecutivo, sobre todo en las sucesivas Juntas militares se vio afectada por un proceso de toma de decisiones fragmentado y normas de procedimiento proclives a generar un sistema carente de control jerárquico y efectividad. En cambio, el arreglo político-institucional del gobierno de Pinochet fue capaz de actuar con sustancial autonomía respecto de todo tipo de oposición interna, ya que entre 1977 y 1979 logró controlar la Junta y bloqueó cualquier desafío políticoinstitucional interno (general Leigh). Dado que la autonomía y el control son un punto clave que condiciona el grado de influencia de los actores internos en la política exterior, a los efectos del presente trabajo no importa tanto si están bajo régimen democrático o autoritario. En consecuencia, sostengo que la «autonomía relativa es más importante que el tipo de régimen» (Ripsman 2009, 190).

En síntesis, la investigación constituye un intento de explicar la evolución de la dinámica conflicto/ cooperación entre ambos países, poniendo de relieve las condiciones internas que llevaron al fin del conflicto. Sin negar la importancia del papel del Vaticano, la investigación sugiere que analizar los procesos de toma de decisiones en política exterior que estudian la interrelación entre los objetivos de los actores políticos y el mecanismo institucional existente sirve más para comprender el fin del conflicto entre Argentina y Chile.

El marco analítico de la investigación se basa entonces en el supuesto de que «la fuente de toda política internacional y de todos los cambios en la política internacional son resultado de la acción individual o colectiva de los seres humanos» (Hudson, 2007: 6). Por 
lo tanto, para comprender plenamente la cooperación entre ambos países es fundamental analizar los patrones de cambio y continuidad de su política exterior durante la crisis.

Sin negar que una convergencia de factores globales y regionales efectivamente generó incentivos para una mayor cooperación entre la Argentina y Chile, este trabajo sostiene que hay que analizar nuevas variables para explicar por qué en 1984 se pudo llegar a un acuerdo exitoso.. Contrariamente a lo que sostiene la blibliografía respecto de la existencia de una "cultura diplomática», en este caso se parte de la base de que en los años setenta nos encontrábamos en un escenario o zona del mundo en que los países no tenían un apego muy sólido a las normas internacionales. No primaba el respeto por derecho internacional o el apego a regimenes internacionales. La diferencia fundamental, en el caso del Beagle, puede explicarse mejor en función del cambio y el control en la distribución del poder interno en ambos países.

\section{EL PROCESO DE TOMA DE DECISIONES EN ARgentina Y CHILE}

\section{a) La politica exterior chilena: error de percepciones}

El golpe de Estado de 1973 y la posterior violación sistemática de los derechos humanos terminó con el status democrático de Chile ante la comunidad internacional. La política exterior chilena perdía su "prestigio diplomático» (Van Klaveren, 1984), su influencia y la percepción del país en América Latina y en el mundo cambiaba radicalmente. Si bien sus líderes estaban conscientes del cambio, no dimensionaron correctamente de qué manera podía afectar la negociación con Argentina.

Con todo, a nivel interno, el gobierno logró una alta cohesión y unidad de mando entre las fuerzas armadas. Para lograrlo, primero el general Pinochet tuvo que erradicar potenciales competidores dentro del cuerpo militar. Mediante la aplicación de una política de nombramientos y de jubilación de militares con mayor jerarquía y prioridad en el escalafón, Pinochet se dedicó luego a controlar la Junta de Gobierno, siendo clave la remoción del general Leigh en 1979 (Cavallo y Serrano, 2003; Hunneus, 2000). En efecto, tras el golpe de Estado, Pinochet fue construyendo y consolidando su poder central ligado a una doctrina de la seguridad nacional y un principio de control jerárquico (top-down) que caracterizó tanto al gobierno como a la cancillería chilena. La subordinación de la política exterior en la figura de Pinochet y un grupo de asesores localizados en la Cancillería (Dirección de Planificación), fueron claves para generar un nivel de autonomía suficiente para que nadie desafiara su control sobre las decisiones de política exterior.

Sin embargo, hay dos situaciones previas que permiten entender crítica- 
mente cómo Chile reaccionó y condujo el resultado del laudo arbitral en 1977. En primer lugar, la cancillería enfrentaba desafíos internos e institucionales. $\mathrm{Al}$ igual que en Argentina, el ministerio había sido asignado a la armada. Aquí la figura del canciller, el Almirante Patricio Carvajal, es clave para entender los primeros conflictos internos. Fue una figura altamente controversial, que se hizo sentir tanto en el exterior como en el país bajo su 'cruzada contra el comunismo'. Como lo describió el coronel Videla: «a Carvajal le toco la época más dura, tenía poco manejo político [y estaba] marcado ideológicamente». En la práctica, ello se tradujo en la persecución y expulsión de diplomáticos afines al gobierno de Allende, todo ello con la «ayuda» de miembros del cuerpo diplomático que delataron a sus colegas. La Dirección de Planificación no fue solo la oficina de enlace entre Presidencia y Cancillería, sino también donde se institucionalizo dicha práctica política. Como señala van Klaveren, «había una estructura paralela, que se concentraba en la Dirección de Planificación que era temida por los diplomáticos de carrera». Según van Klaveren y Durán, la Dirección era vista como un «instrumento de control político e ideológico» para quienes estaban en contra del régimen de Pinochet. Como consecuencia no hubo voluntad de intervenir o criticar las decisiones de política exterior, había más bien, como describe van Klaveren "una estrategia de supervivencia en el cuerpo diplomático chileno». Esto contrasta claramente con la realidad del
Ministerio argentino de Asuntos Exteriores, donde la distribución del poder se caracterizó por la fragmentación del poder entre las Fuerzas Armadas en los mandos medios y superiores de la cancillería, más que una persecución ideológica a los diplomáticos.

Sin duda, este ambiente políticoinstitucional afectó el desempeño de la política exterior chilena: bajo nivel de confianza y cohesión burocrática. Sin embargo, en los primeros años esto no fue tan evidente. Lo que sí se fue generando, según María Teresa Infante, fue una «suspicacia entre los miembros de la cancillería chilena». Según la diplomática chilena, «había un nivel de desconfianza ideológica, profesional y de liderazgo entre los equipos negociadores oficiales y miembros regulares del Ministerio» que afectó el desempeño de la política exterior chilena en la negociación con Argentina. En segundo lugar, esta actitud distante hacia el cuerpo diplomático se refleja en la ejecución de una diplomacia militar paralela y altamente ideológica, si bien tradicionalmente, como señala van Klaveren, los «presidentes chilenos no han confiado en la Cancillería» ya que «tienen dudas sobre el papel de los diplomáticos». En el caso del régimen de Pinochet, sin embargo, la implementación de una diplomacia militar fue una fuente adicional de quiebre y tensión, que se expresó en términos institucionales (exonerados) y en una política altamente ideologizada (anticomunista), a diferencia, del pragmatismo allende los Andes. 
En términos de política internacional, Chile se encontraba en escenarios adversos en tres frentes: una disputa bilateral (virtual guerra con Argentina), un escenario vecinal complejo (tensiones geopolíticas con Perú y Bolivia), y ante la comunidad internacional como un Estado paria, sin aliados ni apoyo de las organizaciones internacionales.

En suma, la orgánica interna de la cancillería no estaba consolidada ni cohesionada para enfrentar una crisis de envergadura como la del Beagle. Sin duda las negociaciones bilaterales con Argentina durante 1977-1978 no solo confirman algo que era de conocimiento más generalizado, es decir, el aislamiento internacional de Chile ante la comunidad internacional, sino que muestran a un ministerio fragmentado que afectó su desempeño en el ámbito internacional. Asimismo, la exacerbada orientación ideológica que impuso Pinochet no fue funcional para enfrentar la crisis del Beagle. Chile no estaba preparado ni supo dimensionar la crisis con Argentina. La carencia de prestigio y cohesión interna en la cancillería, y por consiguiente, su nula influencia para conseguir apoyo en la comunidad internacional se mostraría con toda crudeza en los meses siguientes. Nadie convencería a Argentina de respetar el laudo de 1977. En efecto, una vez que se conoció el fallo del tribunal internacional, Chile careció de una estrategia clara y definida. Se apegó correctamente a su tradicional cumplimiento del derecho internacional, toda vez que el laudo le fue favorable, y si bien como instrumento de política exterior esta estrategia político-jurídica resultó predecible y correcta fue insuficiente para resolver la disputa bilateral. La estrategia definida por Pinochet y sus asesores no tuvo en cuenta otros factores, o más bien, no los sopesó en su justa medida. De hecho, como María Teresa Infante persuasivamente señala «Chile no evaluó adecuadamente su nuevo estatus en América del Sur, especialmente con Argentina». Más importante aún, las negociaciones con Argentina revelaron la vulnerabilidad de Chile en la defensa de sus propios intereses y objetivos. Francisco Orrego Vicuña, asesor jurídico y miembro del equipo negociador señalaba que "Chile tenía un hándicap negativo que afectó su desempeño» durante la crisis.

El problema se acentuó al presumir erradamente que la diplomacia militar que había sido eficaz para sortear conflictivos momentos con Perú y Bolivia a mediados los años setenta podía ser replicada al caso del Beagle. Antes del golpe militar, las relaciones vecinales habían sido dominio de políticos y miembros de la cancillería, pero el éxito parcial o las estrategias de contención aplicadas por Pinochet a los vecinos del norte aumentó la impresión de los asesores militares de que en este caso la estrategia vecinal debía seguir el mismo patrón.

En efecto, en 1976-1977 los delegados del Estado Mayor de las fuerzas armadas de Bolivia, Chile y Perú habían llegado a un acuerdo que estableció mecanismos de cooperación y colabo- 
ración entre sus miembros como forma normal de abordar las relaciones entre Estados. Con tales antecedentes, Pinochet pensó que el éxito diplomático logrado con Perú podía replicarse en la crisis de Beagle. La evidencia revela que esta diplomacia paralela o militar no era el mejor camino para resolver las diferencias entre Argentina y Chile. Entre 1977 y 1978 las negociaciones con Argentina a menudo fueron realizadas por los enviados militares de Pinochet, sin pasar por los profesionales de la cancillería. En lugar de depender de una agenda negociada previamente e internalizada por las cancillerías, los gobiernos militares llevaron a cabo discusiones informales. Fue en estas circunstancias que se gestó la misión Contreras (Jefe del Servicio de Inteligencia) en Buenos Aires el 13 de enero 1978. Con el fin de resolver la disputas pendientes, las fuerzas armadas de ambos países se reunieron bajo la premisa de que los diplomáticos se centran demasiado en la "politiquería» $\mathrm{y}$ en normas internacionales y no en forma directa y eficiente. Varios de mis entrevistados en Santiago y Buenos Aires confirman la percepción negativa de las fuerzas armadas respecto de la diplomacia convencional. Con todo, en los primeros años de la crisis el fracaso de la diplomacia militar tendría consecuencias negativas. El coronel Ernesto Videla, jefe del equipo negociador chileno reconocería que:

"Cuando Pinochet decidió emplear un canal político alternativo, a través de Contreras como emisario especial, y en paralelo a la participación del Ministro de Relaciones Exteriores (personal diplomático), el resultado era debilitar la estrategia chilena a largo plazo. El mensaje para Argentina era que un enfoque diplomático era conducente al fracaso, mientras que, por el contrario, la diplomacia militar conduciría al éxito».

Chile no solo se estaba aislando del concierto internacional, en especial, entre las grandes potencias de occidentales, sino que comenzó percibir cómo dicho "hándicap negativo» afectaba su relación con Argentina. En este contexto, en la crisis de Beagle el presidente Pinochet sintió mucho el peso de la responsabilidad histórica, el que paradójicamente no tuvo con la violación de los derechos humanos. Es decir, estuvo muy consciente de la responsabilidad de llevar a Chile a la guerra y en definitiva ello lo llevó a adoptar una posición defensiva en el manejo de la política exterior.

\section{b) La politica exterior de Argentina}

En Argentina, la variable estructural más importante, y la clave para entender el proceso de toma de decisiones en la Junta Militar, fue la fragmentación del poder entre las tres ramas de las fuerzas armadas y dentro de ellas. Desde 1976, los respectivos comandantes en jefe habían instalado, al igual que en Chile, un régimen militar encabezado por el general Jorge Videla. El máximo órgano del Estado era la Junta Militar, en la que cada uno de ellos tenía la 
misma cuota de poder. Mientras que los comandantes representaban a sus ramas, estos no eran independientes de su cuerpo de oficiales (Comités) (Novaro y Palermo, 2006). La autonomía de los generales y almirantes y la disputa entre ellos tuvo por consecuencia que los altos mandos de cada rama se reunieran por separado para discutir y evaluar los problemas coyunturales, entre ellos el conflicto de Beagle con Chile.

Esta innovación institucional se debe mucho a la firme influencia y poder del almirante Emilio Massera, quien logró recuperar para la Armada las posiciones perdidas durante los enfrentamientos intra-militares de 1962 y 1966 (Torres, 2008). La presidencia era un cargo ejecutivo que en definitiva estaba subordinado a la Junta. Este ente orgánico podía vetar decisiones presidenciales por una mayoría de dos tercios, o deponer al presidente con la unanimidad de sus miembros. Las funciones de gobierno inicialmente se dividieron en tres, y el ejercito controlaba el gabinete presidencial (Navarro y Palermo, 2006). Es importante destacar que, al igual que en Chile, la Armada se hizo cargo del manejo de la cancillería y de la puesta en práctica de la política exterior. En el caso de Chile, el poder de la armada estuvo bajo la dirección del almirante Merino, quien supo conjugar una estratégica alianza de poder con Pinochet. Sin embargo, en el caso argentino, desde el comienzo al interior del gobierno fueron bien conocidas las ambiciones políticas del almirante Massera, que contaba con amplio respaldo entre la oficialidad y los mandos medios. Su belicosa posición en relación con Chile y las veladas criticas a la conducción del presidente Videla no solo acrecentaron su poder en la Armada sino que también entre varios generales del ejército.

El hecho de que se aplicara una política de equilibrio institucional dentro de las ramas de las fuerzas armadas incrementó las disputas de poder ya que las tres buscaban tener representación más o menos proporcional. Si bien la Armada estaba poco representada en la Cancillería, en los demás ministerios dominó la lógica del equilibrio institucional entre las tres ramas. Esto dio lugar a que, entre otras cosas, muchos sectores de mandos medios tuvieran mucho poder, entorpecieran el flujo de información y generaran cuellos de botella en la toma de decisiones (Tulchin, 1984).

A diferencia de Chile, para entender el proceso decisorio argentino hay que tener en cuenta las dictaduras militares anteriores y por ende el rol gravitante de las fuerzas armadas. Según Battaglino «durante la dictadura de 1966-1973, si bien fue una dictadura militar hubo escasa participación de los militares en la toma de decisiones. Más bien primaron los civiles bajo la lógica de evitar la politización de las FFAA. Con el paso del tiempo esta definición política trajo crítica y descontento dentro de las FFAA». El fracaso de esta estructura política estuvo en mente de los generales y almirantes que tomaron el poder una vez más en 1976. Julio Hang, ex 
Teniente General, confirmó las aprensiones de los altos mandos militares al sostener que «para los jóvenes militares argentinos, el conflicto del Beagle era un tema pendiente, que debido a la debilidad de los gobiernos democráticos anteriores, no había sido resuelto. Era un conflicto histórico permanente». Cabe resaltar entonces las diferencias históricas entre ambos gobiernos militares. En relación con el manejo de la disputa del Beagle, es posible identificar una brecha entre civiles y militares y entre las distintas dictaduras argentinas que no fue tan acentuada entre la elite militar y política chilena. La distribución del poder en ambos lados funcionó bajo distintas lógicas, marcadas por coyunturas y antecedentes históricos diferentes.

En este sentido, en lo que respecta a Chile, Andrés Fontana sostiene que «las fuerzas armadas argentinas fueron construyendo una identidad de animosidad durante la década de los setenta». Mis entrevistados en Santiago y Buenos Aires concuerdan con esta apreciación en el sentido de que en ambos países, en especial entre las armadas, fue consolidándose, en términos simbólicos, una identidad hostil que se vio incrementada por el nacionalismo y el chovinismo exacerbado en ambos lados de los Andes. No es casual que ambas armadas hayan desempeñado un papel importante siendo los actores más beligerantes en sus respectivos gobiernos. La crisis de Beagle se había convertido en una disputa marítima entre ambos Estados que emanaba de la proyección de la frontera marítima, ya sea hacia el Pacífico o el Atlántico, y que no había sido resuelta del todo por el laudo arbitral. Acá hubo un efecto espejo en el que las percepciones de pérdida territorial y marítima son completamente simétricas en ambos países. Las islas se veían como un símbolo de la soberanía del país.

A la falta de densidad política y cohesión institucional inicial del ministerio chileno, el caso argentino se caracterizó por las disputas públicas entre el almirante Massera y el presidente Videla. El objetivo político de la Armada argentina era alcanzar la presidencia y Videla era visto como un obstáculo para lograr este fin. Fontana afirma que "la armada argentina había estado discutiendo la posibilidad de una guerra para recuperar las Malvinas desde 1976». Una guerra contra Chile era funcional para el objetivo institucional de la Armada argentina, en especial para el almirante Massera y su camarilla, de tomarse el poder tras un hipotético triunfo en el Beagle. De hecho, la guerra de las Malvinas no se descartó. Era una cuestión de prioridades y timing político de las fuerzas armadas en su conjunto. En efecto, los entrevistados en Buenos Aires en gran medida concuerdan en señalar que la crisis del Beagle fue de un "falso nacionalismo o invención política» creado por la Junta militar. Las islas del Beagle no eran parte ni estaban incorporadas en la cultura política argentina. En el colectivo imaginario, y en comparación con las islas Malvinas, para la ciudadanía argentina el Beagle 
no constituyó un hecho de desgarramiento territorial de la importancia que sí tenían las Malvinas.

\section{EL DESCONOCIDO ROL DE Estados Unidos}

El objetivo de esta sección es analizar cómo los factores internacionales afectaron la implementación de la política exterior argentina y chilena durante la crisis. Hasta ahora poco contextualizada y analizada, los factores internos e internacionales condicionaron en distinta medida la política exterior argentina y chilena. Según las condiciones estructurales nacionales de cada país, el proceso de toma de decisiones varió de acuerdo con la interacción entre las limitaciones nacionales e internacionales. En efecto, la complejidad y la dinámica de la crisis no eran simplemente una cuestión bilateral. Entre los factores críticos ya identificados son múltiples los que se desarrollaron más allá de las fronteras de ambos países a finales de 1977. En su conjunto, dichos factores externos generaron un nuevo escenario que obligó a los tomadores de decisiones a reconsiderar sus estrategias.

En la primera parte de la presente sección se analiza el papel clave que desempeñaron los Estados Unidos. Se detalla cómo en este país había distintos criterios para enfrentar la crisis. Se revela de alguna manera cómo el gobierno de Carter también estuvo sujeto a disputas internas durante la definición de la política exterior y cómo políticas previas de largo plazo aplicadas en la región (lucha contra el comunismo) se enfrentaron con temas nuevos de la agenda; los derechos humanos. La resolución de la crisis del Beagle a menudo se ha explicado en relación con el papel clave desempeñado por el Vaticano. Tanto Argentina como Chile se disputan la idea de quién invitó a la Santa Sede a mediar. Sin embargo, documentos recientemente desclasificados en Estados Unidos, y entrevistas con actores clave, como Robert Pastor y Zbigniew Brzezinski, cuentan una historia diferente.

\section{LA NUEVA AGENDA DEL PRESIDENTE CARTER}

Cuando el presidente Carter llegó al poder en 1977, una de sus principales preocupaciones fue la violaciones de los derechos humanos en América Latina. Carter estaba decidido a hacer de esto una pieza central de su política exterior. Como consecuencia, las relaciones de Estados Unidos con los gobiernos militares de la región se vieron afectadas de distintas maneras. A pesar de la clara voluntad política de Carter, varias autoridades e instituciones de su administración fueron contrarias a la iniciativa del presidente en materia de derechos humanos. En este contexto, la crisis del Beagle se presentó como uno de los primero desafíos para su nueva política exterior en la región. Por un lado, estaba el Departamento de Estado que impulsaba una nueva política de 
derechos humanos en América Latina; por el otro, al Departamento de Defensa, y en particular al Pentágono les preocupaba más bien cómo la crisis de Beagle afectaría el equilibrio y la seguridad regional. En términos bilaterales, la nueva política de derechos humanos era contraria a los intereses de seguridad en la lucha contra «el comunismo internacional» y las insurrecciones en la región.

Como se indica en la sección anterior, Chile se encontraba en una situación regional y global de total aislamiento. En cuanto a la relación a bilateral con Estados Unidos, la situación era altamente compleja. A la violación de los derechos humanos se sumaron la enmienda Kennedy y el coche-bomba que mató al ex ministro Orlando Letelier. El caso de Argentina no era muy distinto del de Chile. Estados Unidos redujo los contactos con las fuerzas armadas, se prohibieron las exportaciones militares, se retuvieron los préstamos bilaterales y el gobierno estadounidense utilizó su poder de veto en los organismos financieros multilaterales (Wright, 2007). En la renovada atmósfera de la Guerra Fría de fines de los años setenta, la invasión soviética de Afganistán y la victoria sandinista de 1979 en Nicaragua eran factores político-estratégicos suficientes para cuestionar la nueva agenda de Carter. En los sectores de la defensa se argumentaba que Estados Unidos debía pasar por alto las violaciones de los derechos humanos y tolerar las dictaduras si ellas eran funcionales a la estrategia anticomunista de Estados Unidos en la región.

En este ambiente se encuadran los históricos discursos anticomunistas de las dictaduras de ambos países y así hay que entenderlas, aunque cada uno de ellas tuvo un matiz o estilo diferentes. Aunque la política exterior del régimen militar argentino era totalmente anticomunista, fue oportunista y más pragmática que la de Chile. Cuando Estados Unidos suspendió sus exportaciones de cereales a la Unión Soviética tras la invasión rusa de Afganistán, Argentina se encontró en una situación privilegiada para suministrar trigo a los soviéticos. A pesar del reclamo del gobierno de Carter, el presidente Videla no tuvo problemas en abastecer a los rusos «desde el granero del mundo».

Paradójicamente, aunque las distintas ramas de las fuerzas armadas argentinas tenían diferentes opiniones sobre la forma de enfrentar la crisis del Beagle, había unanimidad en que debía desplegarse una 'guerra sucia' al interior de sus fronteras para combatir los movimientos insurreccionales. La continua represión interna era necesaria y justificada, y la 'guerra sucia' llevada a cabo por los militares en Argentina sirvió para promover la cohesión entre las fuerzas armadas. La unidad de las fuerzas militares en esta materia y la necesidad de negociar acuerdos entre sus distintas facciones, incluyendo la línea dura en el Ejército y la Armada, hizo que en 1977 el gobierno militar argentino y el gobierno de Estados Unidos no coincidiesen en materia de 
derechos humanos (Martin y Sikkink, 1989) pero descomprimía en algo la lucha interna por el poder. En Chile, la situación era diferente. De hecho, según George Landau, embajador de Estados Unidos en Chile, ejercer más presión sobre el gobierno en temas como el caso Letelier llevaría al país "a un mayor nivel de aislamiento generando como respuesta mayor necesidades de autodefensa nacional que revertiría las tendencias imperantes de liberalización. En este último caso, los argentinos se verían motivados a tomar una o dos islas complicado la situación actual y de más largo plazo en la estabilidad regional» (Landau, junio de 1978).

\section{El PRIMER ENCUENTRO DE Carter, Videla y Pinochet}

El primer encuentro del presidente Carter con los presidentes de América Latina se dio con motivo de la Conferencia de Panamá, realizada en Washington en septiembre de 1977. El grupo de asesores de Carter, liderado por Robert Pastor, escogió este importante evento para presentar su nueva política en materia de derechos humanos. De acuerdo con Pastor, "Carter creía en el cara a cara en las negociaciones». Se reunió con Pinochet y Videla porque "Carter quería asegurarse de que entendieran que el tema de los derechos humanos eran importante para su administración». La crisis del canal del Beagle nunca pudo aislarse por completo del contex- to internacional, que de diversas maneras ayudó a darle forma. En efecto, al gobierno de Estados Unidos no le era indiferente un potencial conflicto entre dos países de América del Sur. Con estos antecedentes, Carter definió una pauta de relaciones entre Buenos Aires y Santiago. Es decir, debió equilibrar temas de seguridad regional con su política de derechos humanos. Asimismo tuvo que lidiar con las disputas intragubernamentales que condicionaron la política exterior estadounidense. En resumen, Carter era consciente de que su política de derechos humanos podía generar no solo inestabilidades internas sino también acentuar indirectamente conflictos bilaterales que influirían en la estabilidad regional. El dilema entonces era en qué medida su política de derechos humanos podía afectar la crisis del Beagle.

La guerra era una opción real y buscada por los halcones del régimen argentino. Chile, por su parte, ya se encontraba bajo amenaza estratégica en su frontera norte (Perú y Bolivia). El escenario tradicional (hipótesis 3), surgía con fuerza entre las fuerzas armadas chilenas. Es decir, en la mente de los asesores de Pinochet rondaba un potencial conflicto fronterizo con los tres países vecinos. Una de las grandes obsesiones de los militares chilenos ha sido la falta de profundidad estratégica del país y su división en dos partes (y cómo asegurar las líneas de abastecimientos). Sin duda, la mediación surgió como forma de salir del estancamiento de la negociación, tanto para resolver los cuestiona- 
mientos internos (Almirante Merino y General Leigh) como para enfrentar la vulnerabilidad externa. En efecto, como lo señala un documento desclasificado del Departamento de Estado «algunos sectores más duros creen que Chile ha sido demasiado blando en su enfoque de las negociaciones con Argentina» (DIADIN, 1978).

De esta manera, la mediación fue tomando forma como camino para resolver los problemas internos y externos. A raíz de las violaciones de los derechos humanos, ambos países enfrentaban graves sanciones internacionales. Mientras que el aislamiento internacional estaba afectando la escasa influencia chilena en la negociación, Argentina no lograba resolver sus disputas internas. Así, para el presidente Videla la mediación surge como una opción para cambiar el escenario político ante sus rivales en el país. Ambos países se encontraban ante una escalada de las hostilidades. Las acusaciones de violaciones de los derechos humanos formuladas ante la comunidad internacional no hacían más que acrecentar la vulnerabilidad y el desprestigio de ambos países.

Según Robert Pastor, Argentina y Chile buscaban retomar la antigua colaboración estadounidense en la lucha contra el comunismo en América Latina. Para este autor, la disputa del Beagle fue vista por Argentina y Chile "como una oportunidad para sacar el tema de los derechos humanos de la agenda que había puesto en marcha el presidente Carter». La idea, según Pastor, era involucrar al gobierno de
Estados Unidos como mediador en el conflicto, como resultado de lo cual el gobierno de Carter se vería obligado a abandonar la política de derechos humanos durante el proceso, ya que el rol de mediador sería incompatible con la defensa de los derechos humanos.

En efecto, de acuerdo con documentos oficiales estadounidenses desclasificados en 2012, «el acercamiento chileno a Estados Unidos para mediar en la disputa del canal de Beagle con Argentina revela algunas esperanzas de buenas relaciones con Estados Unidos» (National Foreign Assessment Centre, enero de 1978). Otro informe de la Casa Blanca revela que «en varias oportunidades el gobierno argentino ha expresado su receptividad al involucramiento directo de Estados Unidos o la mediación, pero podria interpretarse fácilmente como un llamado a la OEA, lo que beneficiaria a los chilenos que tienen ventaja jurídica en la disputa» (National Foreign Assessment Centre, diciembre de 1978).

Es más, Pastor señala que «desde elevados niveles del Pentágono le indicaban, que si se decía no a la mediación, entonces tú [Pastor] vas a ser responsable de una guerra en el Cono Sur. Así que no sabía que hacer. No quería que Estados Unidos entrara como mediador. No quería [tampoco] que Carter entrara en ella». Al interior de Ejecutivo se enfrentaban distintas prioridades y el dilema era mediar o no mediar. En consecuencia, no solo se observaban conflictos al interior de Argentina y Chile sino también dentro de Estados 
Unidos. Como en todo proceso decisional, se producen choques de liderazgos y entre organismos intergubernamentales que por momentos paralizan la toma de decisiones.

El asesor de Seguridad Nacional estadounidense indicó que no quería legitimar «nuestra relación con dos gobiernos militares represivos». Pastor señala que «no quería dañar la política de derechos humanos, que es lo que estaban tratando de hacer. Y por otro lado, tampoco quería una guerra». El dilema, según Pastor, era que no estaba seguro de si ambos países «estaban blufeando con el fin de conseguir que cambiáramos nuestra política de derechos humanos o si realmente estaban próximos a una guerra. Era muy difícil decirlo». Desde Chile, y pensando en una relación bilateral a largo plazo, el embajador Landau analizaba la crisis de Beagle y el asesinato de Letelier concluyendo que "al adoptar decisiones sobre la cuestión táctica también debemos considerar si las acciones servirán para fortalecer a Pinochet (y quizás retrasar el regreso a la democracia), o alternativamente, dejar a un gran número de chilenos creyendo que Estados Unidos desempeñó un papel dominante en el derrocamiento de este gobierno» (Landau, 1978). Como se observa, las intervenciones de Estados Unidos en el Cono Sur tenían muchas aristas políticas y estratégicas, paralelas y entrelazadas, que hacían más compleja la convivencia regional.

A medida que pasaban las semanas en 1978, Pastor revela que «los milita- res argentinos, chilenos y de Estados Unidos estaban muy preocupados por la forma en que la política de derechos humanos había alterado sus relaciones, hasta el punto que estas relaciones pudiesen verse irrevocablemente dañadas». Todos estaban ansiosos por restablecer las antiguas buenas relaciones de cooperación en defensa y seguridad. Pastor señala que pasó mucho tiempo con el personal del Pentágono argumentando sus posiciones. El Pentágono estaba tan molesto con la nueva política puesta en marcha por el presidente Carter que «intentaron variadas formas de convencerme que renunciara a ella y me diera cuenta de la importancia de estos dos países» en la región.

Según Pastor, es en este contexto y dado el escaso margen de maniobra en que se encontraba el Ejecutivo estadounidense que surge la opción y figura del Papa Juan Pablo II como mediador. Aquí resultaría clave la figura de Brzezinski. Ambos de nacionalidad polaca, como es natural conversaban en su lengua materna y según Pastor, esto ayudó a generar lazos de confianza y acercamiento. De esta manera, en diciembre de 1978, Brzezinski revela por primera vez cómo se gesto el ingreso del Vaticano en la mediación:

«Tuve una breve conversación con el Papa donde abordamos un conjunto amplio de temas. Puse el tema de un posible conflicto entre Chile y Argentina por una disputa territorial, y le dije que si había un conflicto entre dos importantes países católicos en América del Sur eso enviaría una mala señal 
para la región y el mundo, y le pedí si podía ayudar a prevenir el conflicto, el Papa dijo que lo consideraría y, tras de un tiempo, decidió utilizar el Vaticano para mediar» ${ }^{3}$

Brzezinski y Pastor pensaban que la intervención del Papa podría ser funcional a sus intereses de seguir con su política de derechos humanos, y al mismo tiempo, evitar una guerra en la región. Pastor relata que al regresar al Pentágono con la nueva fórmula (Papa como mediador), les dijo «tengo algo mucho mejor. El Papa lo hará. Miré sus caras, y era claro para mí que los había impresionado. Intentaron acorralarme, y resultó que ellos terminaron entrampados. No podían decirle que no al Papa. Fue así como pudimos mantener nuestra política de derechos humanos y resolver el problema [del Beagle]».

Los documentos desclasificados indican que a ambos gobiernos les interesaba la participación de Estados Unidos en la crisis. Estos apoyan la declaración de Pastor de 2012, sin embargo, no son concluyentes acerca de las verdaderas intenciones de los presidentes Pinochet y Videla. Es decir, una supuesta coordinación de ambos gobiernos para descartar la agenda de los derechos humanos. No hay duda que no es posible confirmar ni negar dicho opción.

Correo electrónico recibido el 8 de abril de 2012. Zbigniew Brzezinski fue Consejero de Seguridad Nacional del Presidente Jimmy Carter entre 1977 y 1981.

\section{LA VERSIÓN DEL CORONEL VIDELA}

El coronel Videla rechazó la versión de Pastor. "Estos señores no pueden estar más perdidos con lo que sucedió». Tras contradecir la versión estadounidense, el coronel Videla subrayó que «la gestión con el Papa la hizo Cubillos personalmente, a través del nuncio. Habíamos estado trabajando en esta opción por largo tiempo, desde que evaluamos negativamente el futuro de la negociación. Videla destacó que «el mayor pecado de una gran potencia como Estados Unidos fue no haber levantado la voz cuando Argentina declaro insanablemente nulo el laudo en enero 1978». "Les dijimos a ellos», se quejó Videla, «el riesgo militar en el Cono Sur, pero no hicieron nada al respecto".

A continuación Videla, resalta la relación de amistad que entabló con George Landau, embajador de Estados Unidos en Chile. En este marco, según Videla el Departamento de Estado no tomó debidamente en consideración el análisis de Landau sobre la situación en el Cono Sur. Ciertamente esto no coincide con la visión del propio Pastor y los documentos desclasificados tanto de Estados Unidos como del Reino Unido. Lo que sí es cierto es la nula reacción diplomática de Estados Unidos ante el rechazo del laudo por Argentina. En muchos casos, los embajadores tienen una visión más cercana y tal vez de mayor conocimiento sobre los eventos locales. Con todo, no se trató de un 
problema de comunicación con Washington, sino más bien de una política estadounidense que debía articular distintos intereses y objetivos. Es decir, la política exterior de Carter le dio mayor énfasis al tema de los derechos humanos (estrategia regional), a la enmienda Kennedy (política bilateral) y al asesinato del canciller Letelier. En concreto, estas eran las prioridades de la política exterior estadounidense, donde muchas se entrecruzaban con consideraciones internas y externas. En suma, la visión del embajador Landau debía converger con una política exterior dictada desde Washington. Y es ahí donde tropezó con mayores problemas el error de percepción del equipo chileno.

Ante la pregunta concreta sobre la opción de Estados Unidos como mediador, Videla fue enfático en señalar que «habría que ser muy tarado (sic) para considerar la opción de Estados Unidos como mediador bajo el gobierno de Carter». Videla estaba consciente de que la opción de la mediación era un "camino más político que jurídico». En este contexto, "dentro del grupo», señala Videla, «estábamos conscientes de nuestros problemas internos [violación de los derechos humanos.], tuvimos presente el riesgo sobre el rol de la Iglesia católica, pero en términos políticos llegamos a la conclusión de que el Vaticano era una buena opción». Videla enfatizó que «si ya teníamos problemas con la Iglesia católica, ¿te imaginas a Estados Unidos como una opción?». En estas circunstancias, «nadie habría entendido y aceptado esa opción [Estados Unidos]». Videla termina la entrevista diciendo que en Chile y Argentina no había ninguna posibilidad de acuerdo entre para que Estados Unidos fuese una opción. En suma, «lo que Pastor te está diciendo no tiene ninguna lógica». Concluye, sin embargo, aceptando la idea de que Brzezinski hubiesea llamado al Papa, «pero solo como consecuencia de la presión chilena a través del embajador Landau».

Meses después, Pastor tuvo conocimiento de la versión de Videla. Según él, «no estaba seguro de que ambas interpretaciones fuesen totalmente incompatibles. Primero que nada aclara, «no sé si hubo una conspiración", pero según él «era obvio que ambos países querían que Estados Unidos abandonara su política de derechos humanos a su respecto». Según Pastor, «el punto es simple: estaba en el interés de Argentina y Chile resolver el problema del Beagle y al mismo tiempo neutralizar la política de derechos humanos. Igualmente, a Estados Unidos le interesaba prevenir una guerra y mantener su política de derechos humanos».

\section{Comentarios Finales}

A lo largo de este trabajo transcurren varios eventos, pero dos de ellos son de capital importancia. Como se dijo, la crisis Beagle no fue un solo conflicto sino una superposición de disputas políticas tanto a nivel nacional como internacional. Se unieron 
enfrentamientos de larga data sobre una disputa fronteriza entre Argentina y Chile, y en forma paralela, se generó una compleja relación entre Estados Unidos, Argentina y Chile. En consecuencia, las tendencias analizadas en el trabajo dan cuenta del debilitamiento de la distinción entre la política exterior y la política interna.

Debido a la coyuntura histórica del derecho internacional (derechos humanos) y a factores nacionales y regionales de la década de los años setenta, Estados Unidos comenzó a asumir responsabilidades nuevas y más directas en la defensa de los derechos humanos en América Latina. De esta forma, por varios motivos para Argentina y Chile, la relativa autonomía de los militares para mantener el control interno de sus gobiernos no implicó que su política exterior se viera afectada por la presión internacional. El margen de negociación no solo se vio limitado por diversos factores internos, en especial en el caso argentino, sino también por la forma en que la política de derechos humanos de Estados Unidos condicionó la dimensión bilateral. Al iniciarse la crisis no hay duda de que los dos países no lo tuvieron presente.

Basándose en su interpretación de la política mundial y en los imperativos de la política interna, los dirigentes argentinos y chilenos eligieron diferentes caminos diplomáticos. La acción de actores internacionales para poner fin a las hostilidades y ofrecer su ayuda en la búsqueda de una solución diplomática forzó una salida pacífica entre Argenti- na y Chile. La yuxtaposición resultante de la política exterior e interior pone de manifiesto una interacción constante entre los actores y el contexto, y esta interacción hizo que la trayectoria del conflicto pasara a un estadio de cooperación entre ambos países. Sin embargo, en un principio, ninguno de los dos esperaba resolver el conflicto con un tercer actor. Chile descansó en la razón jurídica, Argentina en una campaña belicosa.

Dada que la complejidad de la crisis iba en aumento, el proceso de negociación generó nuevos canales de acción política que hicieron más difícil mantener la autonomía y el control de los dos países. Es aquí donde se produce un cambio de una dinámica bilateral a una dimensión global. En efecto, a medida que aumentó la tensión, se involucraron en la crisis más actores nacionales e internacionales, lo que refleja la capacidad de otros actores de influir en el comportamiento de países medianos y pequeños y condicionarlo.

Una de las singularidades de esta crisis es, por una parte, que la estrategia política de la diplomacia chilena se sustentaba en el derecho internacional en circunstancias de que estaba completamente aislada de la comunidad internacional. El desprestigio y la escasa influencia para cambiar la actitud de Argentina fueron explotados por la diplomacia bonaerense que sin duda no tenía incentivo alguno para cambiar el escenario de negociación. El statu quo le favorecía y Chile carecía de una estrategia adecuada. La paradoja es que 
Pinochet haya llegado a la conclusión de que la única salida era cambiar el escenario de negociación, aceptar el involucramiento de un actor internacional, sacrificar (autoritariamente) espacios marítimos, y atenerse a la resolución de un proceso de mediación política. Todo ello, a pesar de tener el derecho internacional en su favor.

\section{BIBIOGRAFÍA}

\section{Fuentes primarias}

CIA. «Argentina-Chile: Beagle Channel Dispute and the Potential for Conflict.» Turner Stansfield, NI IAM 78-1003J, 8 Diciembre 1978.

CIA Operations Center. "Argentina-Chile: The Beagle Channel Crisis.» White House Spot Report, CIA/OC/WHSR 78-215, 13 December 1978.

DIADIN 194-9A. «Chile: rumor grills on.» $\mathrm{N}^{\circ} 02068,13$ Julio 1979.

Fondo Documental volumen 2000. "Chile y la Argentina después de Montevideo (II).» Doc. N99/36, Embajada de Chile en Argentina, Archivos del Ministerio de Relaciones Exteriores de Chile, 1 Febrero 1979.

" "Chile y Argentina después de Montevideo.» Doc. N50/21, Embajador Sergio Onofre Jarpa, Embajada de Chile en Argentina, Archivos Ministerio de Relaciones Exteriores de Chile, 18 Enero 1979.

Fondo Documental volumen 2001. «La mediación papal entre Chile y Argentina.» Doc. N³06/141, Embajada de Chile en Argentina, Archivos de Ministerio de Relaciones Exteriores de Chile, 9 Abril 1979.

Fondo Documental volumen 2060. «Informe reunión Enrique Bernstein con Cardenal Samoré donde se plantea preocupación por actitud argentina.» Doc Sec. 040, Enrique Bernstein, Oficina de Mediación,
Archivos Ministerio de Relaciones Exteriores de Chile, 28 Enero 1981. «Entrevista Coronel Videla con Samoré.» Doc Sec. 206, Colonel Videla, Oficina de Mediación, Archivos Ministerio de Relaciones Exteriores de Chile, 29 Mayo 1981.

National Foreign Assessment Center. «Latin American Briefs.» 11 Enero 1978. . «Argentina's Demand for DryLand Point for Demarcation of Maritime Boundaries.» Sayre Stevens, NFAC-562478, National Intelligence Officers, 18 Diciembre 1978. «Memorandum.» 02045: U.S Ambassador George Landaus, 23 Junio 1978. National Security Council. "Memorandum for Zbginiew Brzezinsky.» Jimmy Carter Library, 28 Junio 1978.

U.S State Department. "Memorandum.» U.S. Ambassador George Landau, $n^{\circ} \mathrm{O} 2045$ 23 Junio 1978.

\section{Fuentes secundarias}

Agüero, Felipe (1998) «Legacies of transition: Institutionalization, the Military and Democracy in South America", Mershon International Studies Review, 48: 384-404.

Allan, Laurence (1999) "Néstor Kirchner, Santa Cruz, and the Hielos Continentales Controversy, 1991-1999", Journal of Latin American Studies, (39) 2007: 747-770.

Allison Graham y Philip Zelikow (1999) The essence of decision: explaining Cuban missile crisis, Second ed.: Addison, Wesley, Logman.

Alvarez Natale, Hugo (1984) Beagle: de brujos y fantasmas a la decisión final, Buenos Aires: Ediciones Politeia.

Arancibia Clavel Patricia y Francisco Bulnes (1999) La Escuadra en Acción, Grijalbo, 2004.

Atkins Pope G. (1999) Latin American and the Caribbean in the International System, Westview Press.

Battaglino, Jorge (2010), «La política militar de Alfonsín: la implementación del control civil en un contexto desfavorable.» en Discutir Alfonsin, Gargarella, Roberto, 
Victoria Murrillo y Mario Pecheny (eds.), Buenos Aires.

Benadava, Santiago (1999), Recuerdos de la Mediación Pontificia entre Chile y Argentina (1978-1985), Santiago: Editorial Universitaria.

Bernstein, Enrique (1989), Recuerdos de un diplomático. Representante ante el Papa Mediador, Vol. IV. Santiago: Editorial Andrés Bello.

Bignone, Reynaldo (1992), El último de Facto. La liquidación del proceso Memoria y Testimonio, Buenos Aires: Planeta.

Buchanan Allen E. y Margaret Moore (2003), States, Nations and Borders: The Ethics of Making Boundaries, Cambridge University Press.

Burr, Robert (1966), By Reason or Force: Chile and the Balancing of Power in South America, 1830-1905: University of California Press.

Calvert, Peter (1983), «Boundary Disputes in Latin America» Conflict Studies (146): 3-28.

Camilión, Oscar (2000), Memorias Políticas. De Frondizi a Menem, Buenos Aires: Planeta, 2000.

Cavaleri, Paulo (2004), La restauración del Virreinato. Orígenes del nacionalismo territorial argentino: Universidad Nacional de Quilmes.

Cavallo, Ascanio y Margarita Serrano (2003), Golpe 11 de Septiembre, Santiago: Aguilar.

Child, Jack (1985), Geopolitics and Conflict in South America. Quarrels among Neighbors: Hoover Institution Press y Universidad de Stanford.

Cisnero, Andrés y Carlos Escudé (2000), Historia general de las relaciones exteriores de la República Argentina Vol. 1-6. Buenos Aires. : Centro de Estudios de Política Exterior: Consejo Argentino para las Relaciones Internacionales: Grupo Editor Latinoamericano.

Collier, Simon y William F. Sater (2004), A History of Chile, 1808-2002, Second ed., Cambridge University Press.

Cortés Conde, Roberto (1993), «The growth of the Argentine economy 1870-1914» en
Argentina Since Independence Simon Collier y William F. Sater (eds.), Cambridge University Press.

Dominguez ,Jorge I. y otros (2003), Boundary disputes in Latin America, Washington DC: United States Institute for Peace.

Donadio, Marcela y Luis Tibiletti (1998), «Strategic Balance and Regional Security in the Southern Cone» en Strategic Balance and Confidence Building Measures in the Americas, Joseph S. Tulchin y Francisco Aravena Rojas (eds.), Washington: The Woodrow Wilson Center Press.

Durán, Roberto (2009), «Ensayo de Análisis Conductual Sobre los Hitos de la Diplomacia Chilena Entre las Primeras y las Últimas Décadas del Siglo XX» Estudios Geográficos LXX, no. 266: 79-96.

Durán, Roberto y Manfred Wilhelmy (2003), «Los principales rasgos de la política exterior chilena entre 1973 y el 2000», Revista de Ciencia Política, $\mathrm{n}^{\circ} 23$.

Escudé, Carlos (1988), «Argentine Territorial Nationalism", Journal of Latin American Studies vol. 20, No. 1, May: 139-165.

Fermandois, Joaquín (2005), Mundo y fin de Mundo. Chile en la politica mundial 1900-2004, Santiago: Ediciones Universidad Católica.

Ferrari, Gustavo (1969), Conflicto y Paz con Chile, 1898-1903, Buenos Aires: Eudeba.

Fontana, Andrés (1990), «La política militar en un contexto de transición: Argentina 1983-1989.» Documento CEDES 34.

Fraga, Rosendo (1997), "Las Fuerzas Armadas 1973-1983 « en Nueva Historia de la Nación Argentina. La Argentina del Siglo XX editado por la Academia Nacional de la Historia, Buenos Aires: Planeta.

Gallo, Ezequiel (1998), «Society and Politics, 1880-1916» en Argentina Since Independence, edited by Leslie Bethell, pp. 79-112, Cambridge University Press.

Garrett, James (1985), «The Beagle Channel Dispute: Confrontation and Negotiation in the Southern Cone", Journal of InterAmerican Studies and World Affairs, 27: 81-109. 
ANDrÉs Villar • El desconocido rol de Estados Unidos en la crisis del canal de Beagle

Gerson, Allan (1977), «The Beagle Channel Affairs", The American Journal of International Law 71, no. 4: 733-740.

Goertz, Gary y Paul Diehl (1993), «Enduring Rivalries: Theoretical Constructs and Empirical Patterns», International Studies Quarterly 37, no. 2: 147-171.

Hagan ,Joe D. (1993), Political Opposition and Foreign Policy in Comparative Perspective, Boulder, CO: Westview.

(2001), «Does Decision Making Matter? Systemic Assumption vs. Historical Reality in International Relation Theory", en Leaders, Groups, and Coalitions. Understanding the People and the Process in Foreign Policymaking Joe D. Hagan y Margaret G. Hermann (eds.) pp. 5-46. Oxford: Blackwell.

Hill, Christopher (2003), The Changing Politics of Foreign Affairs, NY: Palgrave Macmillan.

Holsti, Kalvi J. (1996), The State, War and the State of War, Cambridge University Press.

Hudson, Valerie M. (2005), «Foreign Policy Analysis: Actor-Specific Theory and the Ground of International Relations», FOreign Policy Analysis 1, no. 1: 1-30.

(2007) Foreign Policy Analysis.

Classic and Contemporary Theory. Maryland: Rowman \& Littlefield.

Huneeus, Carlos (2000), El Régimen de Pinochet, Santiago: Editorial Sudamericana, 2000.

Hurrell, Andrew (1998), "Security in Latin America», International Affairs 73, no. 3: 529-546.

(2007) On Global Order. Power, Values and the Constitution of International Society, Oxford: Oxford University Press.

Infante, María Teresa (1984), "Argentina y Chile: Percepciones del Conflicto de la Zona del Beagle», Estudios Internacionales, 67 (julio-septiember): 337-358.

Infante, María Teresa (1988), «La delimitación Marítima en el mar de la Zona Austral» en El Tratado de Paz y Amistad entre Chile y Argentina, Rodrigo Díaz Albónico (ed.), Santiago: Editorial Universitaria.
Kacowicz, Arie (2001), The impact of norms in international society: the Latin American experience, 1881-2001, Notre Dame, Indiana: University of Notre Dame.

Lacaste, Pablo (2003), La imagen del otro en las relaciones de la Argentina y Chile: 1534-2000, Buenos Aires: Fondo de Cultura Económica.

Lanas, Juan Archibaldo (1984), De Chapultepec a Beagle, Politica Exterior Argentina 1945-1980, Buenos Aires: Emece Editores.

Laudy, Mark (2000), «The Vatican Mediation of the Beagle Channel Dispute: Crisis Intervention and Forum Building» en Words Over War: Mediation and Arbitration to Prevent Deadly Conflict, Melanie Greenberg, John H. Barton y Margaret E. McGuiness (eds.), Carnegie Commission on Preventing Deadly Conflict: Rowman \& Littlefield Publishers.

Lobell, Steven E. (2009), «Threat assessment, the state, and foreign policy: a neoclassical realista model» en Neoclassical Realism, the State, and Foreign Policy, Steven Lobell, Norrin Ripsman y Jeffrey W. Taliaferro (eds.): Cambridge University Press.

Maira, Luis (1985) «Las Relaciones EstadosUnidos,» en Las Politicas Exteriores Latinoamericanas Frente a la Crisis, Heraldo Muñoz (ed.), Buenos Aires: GEL, 1985.

Mares, David (1998), «Explaining the Use of Force in Latin America», en International Security and Democracy, Jorge I. Dominguez (ed.), pp. 29-47. (2001), Violent Peace. Militarized Interstate Bargaining in Latin America, NY: Columbia University Press.

Martin ,Lisa L. y Kathryn Sikkink (1993), «U.S Policy and Human Rights in Argentina and Guatemala, 1973-1980», en Double-Edged Diplomacy. International Bargaining and Domestic Politics, Peter B. Evans, Harold K. Jacobson y Robert D. Putnam (eds.)Berkeley: University of California Press.

Meneses, Emilio (1998), Ayuda Económica. Política Exterior y Política de Defensa en Chile, 1943-1973, Documentos de Trabajo $\mathrm{n}^{\circ} 117$, Centro de Estudios Políticos. 
Millán, Victor (1983), «Regional ConfidenceBuilding in the Military Field: The Case of Latin America", en Controlling Latin American Conflicts, Michael A. Morris y Victor Millán (eds.), pp. 89-97, Boulder, CO: Westview Press.

Morris, Michael A. (1983), «Naval Arms Control in Latin America» en Controlling Latin American Conflicts, Michael A. Morris y Victor Millán (eds.), 147-161. Boulder, CO: Westview Press. (1989) The Strait of Magellan International straits of the world, v.11. Dordrecht; Londres: Nijhoff.

Muñoz, Heraldo (1987), «El estudio de las Políticas Exteriores Latinoamericanas", en Formación de la Política Exterior. Los Países Desarrollados y América Latina, Manfred Wilhelmy (ed.), Buenos Aires: GEL.

Muñoz, Heraldo y Joseph Tulchin (eds.) (1984), Latin American Nations in World Politics: Westview Press.

Navarro Meza, Miguel (1998), «A Chilean Perspective on Strategic Balance in South America", en Strategic Balance and Confidence Building Measures in the Americas Joseph Tulchin y Francisco Rojas (eds.), Washington: The Woodrow Wilson Center Press.

Novaro, Marco y Vicente Palermo (2006), Historia Argentina. La Dictadura Militar 1976/1983. Del golpe de estado a la restauración democrática, Buenos Aires: Paidós.

Orrego Vicuña, Francisco (1989), Chile y Argentina: nuevos enfoques para una relación constructiva, Consejo Chileno para las Relaciones Internacionales.

Parish, Randall Jr. (2006), «Democrats, Dictators, and Cooperation: The Transformations of Argentine-Chilean Relations", Latin American Politics and Society 48, no.1 (Spring): 143-174.

Passarelli, Bruno (1998), El delirio armado: Argentina-Chile la guerra que evitó el Papa, Buenos Aires: Editorial Sudamericana.
Pittman, Howart (1984), «Chilean Foreign Policy: the pragmatic pursuit of geopolitical goals» en The dynamic of Latin American Foreign Policies. Challenges for the 1980s Jennie K. Lincoln y Elizabeth G. Ferris (eds.), Westview Press.

Princen, Thomas (1992), Intermediaries in International Conflict, Princeton University Press.

Puig, Juan Carlos (1984), «La política exterior argentina: incongruencia epidérmica y coherencia estructural», en América Latina: Politicas Exteriores Comparadas, Juan Carlos Puig (ed.), Buenos Aires.

Putnam, Robert (1988), «Diplomacy and Domestic Politics: The Logic of Two-Level Games», International Organization 42, no. 3 Summer: 427-460

Quiñones, Carlos (1987), Los recursos novivos y de hidrocarburo en las áreas regidas por el Tratado de Paz y Amistad» en El Tratado de Paz y Amistad entre Chile y Argentina, Rodrigo Díaz Albónico (ed.), Santiago: Editorial Universitaria.

Ripsman, Norrin M. (2009), «Neoclassical realism and domestic interest groups", en Neoclassical Realism, the State, and Foreign Policy, Steven Lobell, Norrin Ripsman y Jeffrey W. Taliaferro (eds.): Cambridge University Press.

Rojas Aravena ,Francisco (2001), «Building a Strategic Alliance. The Case of Chile and Argentina", Pensamiento propio 14, no. Julio-diciembre: 61-97.

Russell, Roberto (1990), «El proceso de toma de decisiones en la política exterior Argentina (1976-1984)», en Política exterior y toma de decisiones en América Latina, Roberto Russell (ed.). Buenos Aires: Grupo Editor Latinoamericano.

(2008), «Democratization and Its

Qualitative Impact on Argentine Foreign Policy», Instituto del Servicio Exterior de la Nación, Diciembre.

(2010), «La Argentina del segundo centenario: ficciones y realidades de la política exterior» en Argentina 1910-2010. Balance del Siglo, Roberto Russell (ed.), Buenos Aires: Taurus. 
ANDrÉs Villar • El desconocido rol de Estados Unidos en la crisis del canal de Beagle

Russell, Roberto y Juan Gabriel Tokatlian (2003), «From Antagonistic Autonomy to Relational Autonomy: A Theoretical Reflection from the Southern Cone", Latin American Politics and Society 45, no. 1 Spring: 1-24.

Sánchez, Walter (1977) Ciento cincuenta años de politica exterior chilena, Santiago: Universidad de Chile.

Scenna, Angel (1981), Argentina-Chile: Una frontera caliente, Buenos Aires.

Sterlin-Folker, Jennifer (1997), «Realist Enviroment, Liberal Process, and DomesticLevel Variables», International Studies Quarterly 41, no.1, March: 1-25.

Taliaferro, Jeffrey W. (2009), «Introduction: Neoclassical realism, the estate, and foreign policy» en Neoclassical Realism, the State, and Foreign Policy, Steven Lobell, Norrin Ripsman y Jeffrey W. Taliaferro (eds.): Cambridge University Press.

Tapia, Luis Alfonso (1998), Esta noche: La Guerra, Santiago: Grijalbo-Mondadori.

Tomassini, Luciano (1991), «Elementos para el análisis de la política exterior», Estudios Internacionales 78 1987: 125-157.

Tomassini, Luciano, Carlos Moneta y Augusto Varas (eds.) (1991), La Política Internacional en un Mundo Postmoderno, Buenos Aires: GEL.

Torres, Juan Carlos (1988), «Argentina since 1946» en Argentina since Independency, Leslie Bethell (ed.): Cambridge University Press.

Tulchin, S. Joseph (1984), «Authoritarian Regimes and Foreign Policy: The Case of Argentina» en Latin American Nations in
World Politics, Heraldo Muñoz y Joseph S. Tulchin (eds.): Westview Press.

Van Klaveren, Alberto (1984), «The Analysis of Latin American Foreign Policies: Theoretical Perspectives» en Latin American Nations in World Politics, Heraldo Muñoz y Joseph S. Tulchin (eds.), Westview Press. (1997), "Continuidad y cambio en la política exterior chilena» en ArgentinaChile: desarrollos paralelos? , Torcuato Di Tella (ed.), Buenos Aires: Nuevo Hacer Grupo Editor Latinoamericano.

Varas, Augusto (1980), «Foreign Policy and National Security Doctrines», Documento de Trabajo, $n^{\circ} 100$, FLACSO-Chile.

Videla, Ernesto (2007), La desconocida historia de la mediación papal. Diferendo austral Chile/Argentina 1977-1985, Santiago: Ediciones Universidad Católica de Chile.

Vio Valdivieso, Fabio (1984), La mediación de su S.S. el Papa Juan Pablo II, Santiago: Editorial Aconcagua.

Waltz, Kenneth (1979), Theory of International Politics, Reading, MA: Addison Wesley.

Wilhelmy, Manfred (1976), Chilean Foreign Policy. Frei Government 1964-1970, (Thesis) PhD Political Science, Princeton University.

(1984) «Politics, Bureaucracy and Foreign Policies in Chile» en Latin American Nations in World Politics, Heraldo Muñoz y Joseph S. Tulchin (eds.), Westview Press.

Wright, Thomas C. (2007), State terrorism in Latin America: Chile, Argentina, and international human rights, Maryland: Rowman \& Littlefield. 